\title{
Dissecting the Chain Length Effect on Separation of Alkane-in-Water Emulsions with Superwetting Microchannels
}

Jian Jin ${ }^{a}$, Hongyun $\mathrm{Li}^{a}$, Kaiqi Zhao ${ }^{a}$, Jun $\mathrm{Su}^{a}$, Lu Xia ${ }^{a}$, Xiaohu Yuan ${ }^{\text {a }}$, Guangming Jiang ${ }^{b}, B o X u^{c}$, Lidong Sun ${ }^{a, *}$

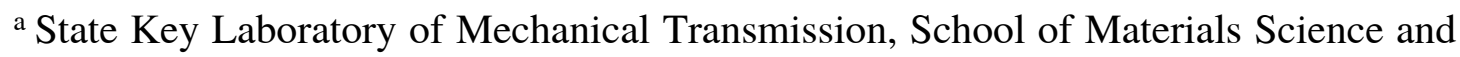
Engineering, Chongqing University, Chongqing 400044, China

${ }^{\mathrm{b}}$ Engineering Research Center for Waste Oil Recovery Technology and Equipment, Ministry of Education, Chongqing Technology and Business University, Chongqing 400067, China

c Jinhai Oil Production Plant, PetroChina Liaohe Oilfield, Panjin 124000, China

*Correspondence, E-mail: lidong.sun@cqu.edu.cn 
Video S1. The infiltration evolution of water and $n$-hexane droplets on superhydrophilic titanium foams under ambient condition.

Video S2. The collision of $n$-hexane jet on the original and superhydrophilic foams under water. 


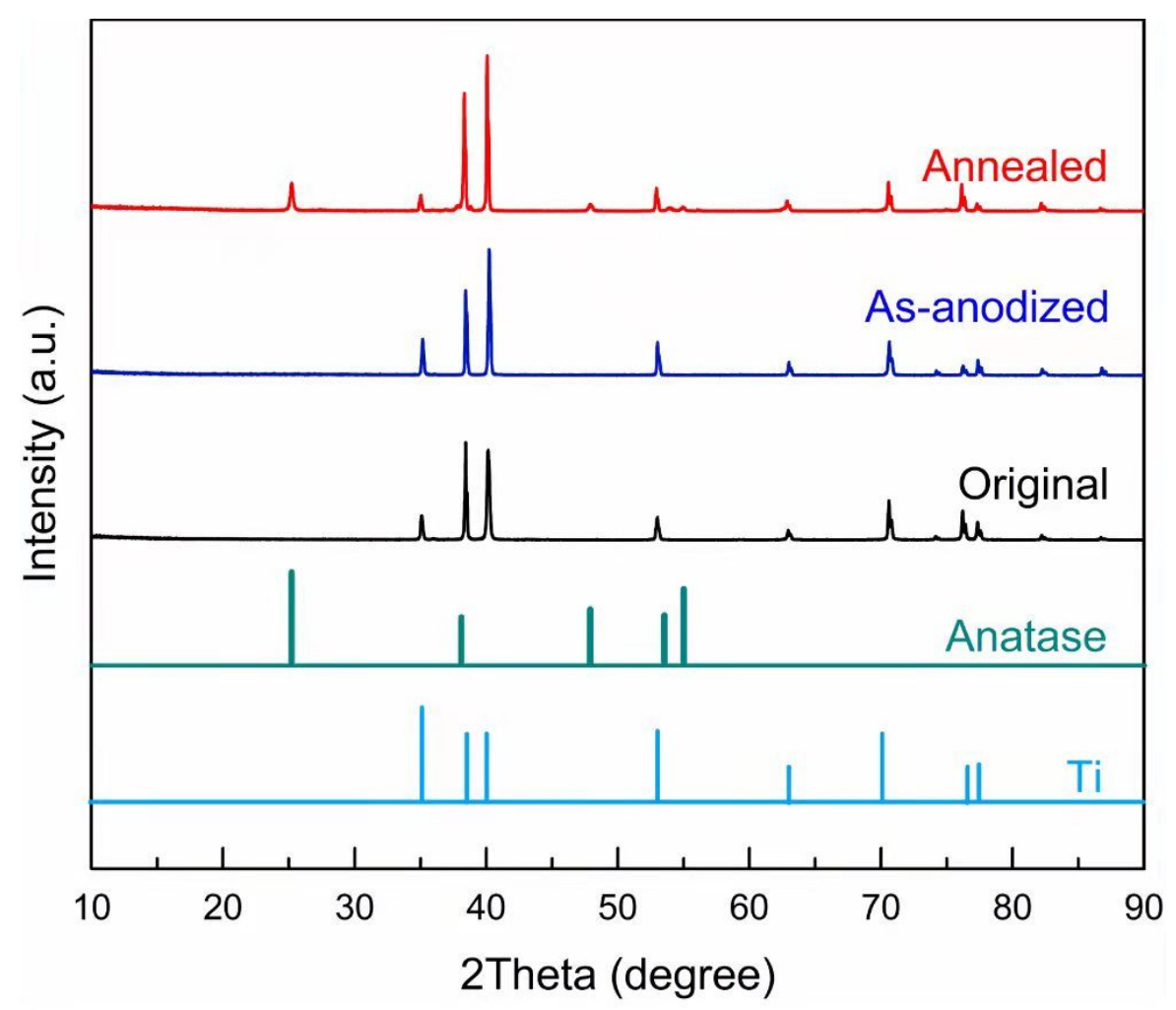

Figure S1. Typical X-ray diffraction patterns of the titanium foams before (i.e., original) and after electrochemical anodization at $40 \mathrm{~V}$ for $3 \mathrm{~h}$ (i.e., as-anodized), and that after annealing at $450{ }^{\circ} \mathrm{C}$ for $3 \mathrm{~h}$ (i.e., annealed), where the standard patterns of $\mathrm{Ti}$ and $\mathrm{TiO}_{2}$ (anatase) are also shown for comparison. The results reveal that the original titanium foams are coated with amorphous $\mathrm{TiO}_{2}$ upon anodization, which crystalizes into anatase structure after annealing. 

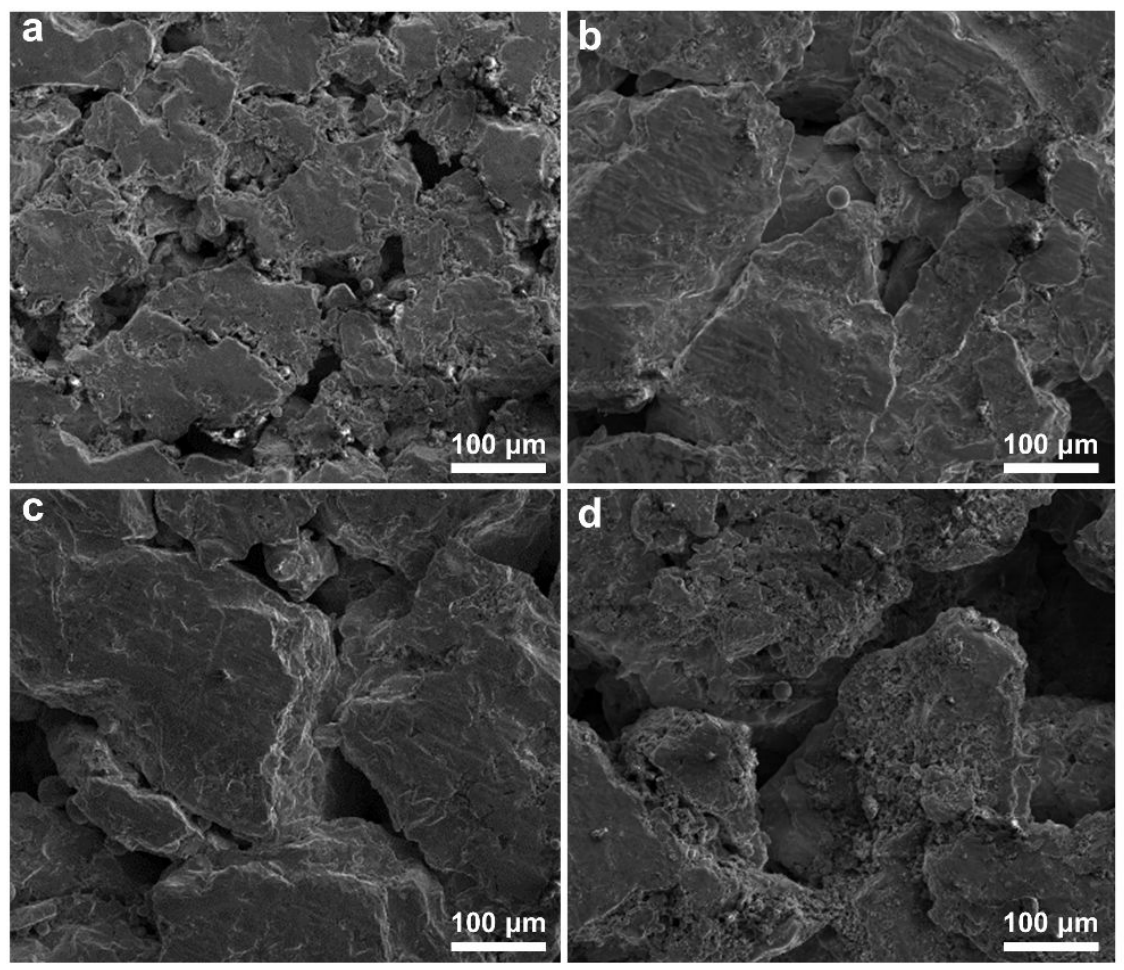

Figure S2. Top-view FESEM images of the original Ti foams with a filtration accuracy of about $10 \mu \mathrm{m}$ (a), $20 \mu \mathrm{m}$ (b), $30 \mu \mathrm{m}$ (c) and $50 \mu \mathrm{m}$ (d). 

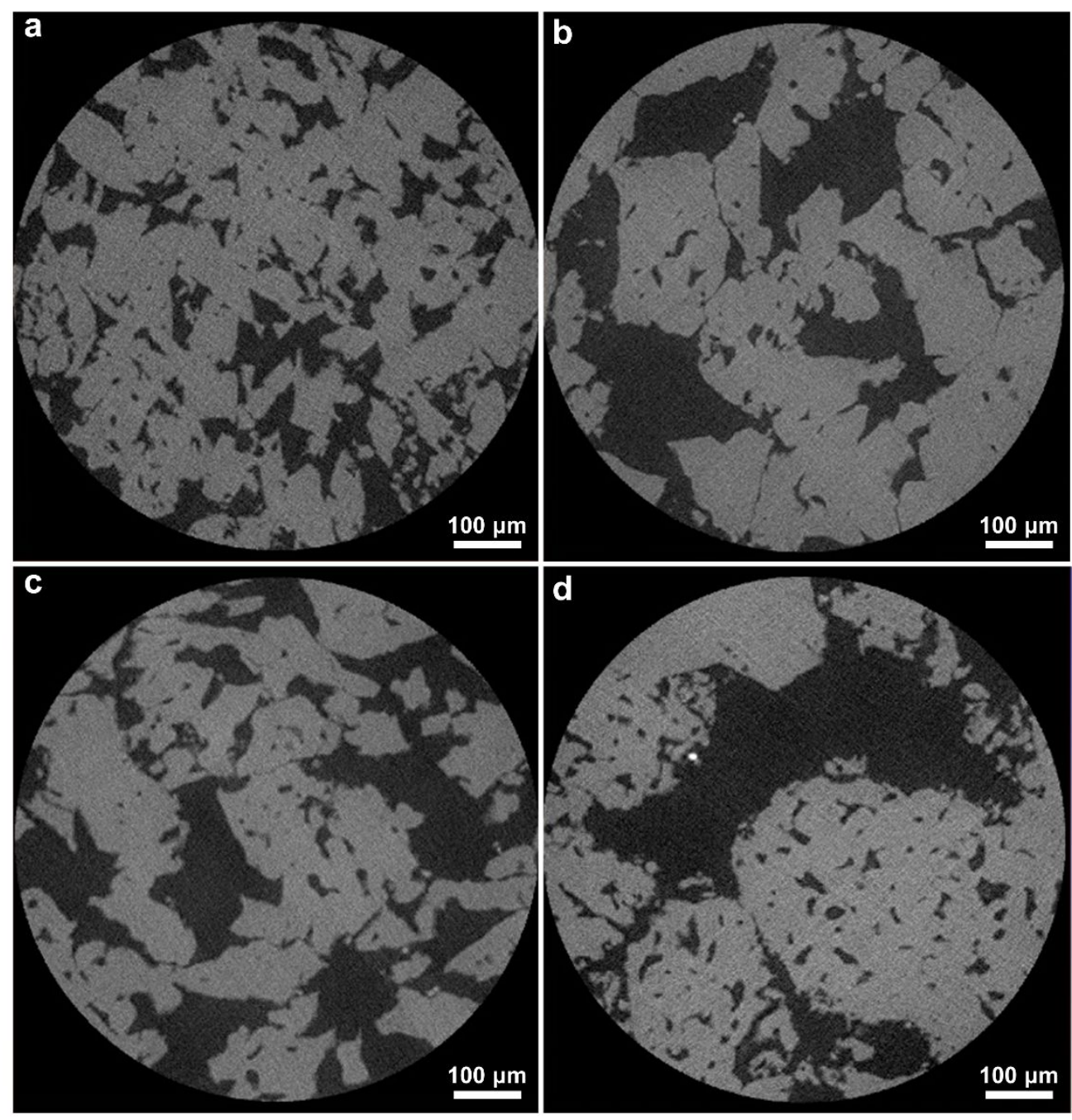

Figure S3. Typical 2D micro-CT images of the original Ti foams with a filtration accuracy of about $10 \mu \mathrm{m}$ (a), $20 \mu \mathrm{m}$ (b), $30 \mu \mathrm{m}$ (c) and $50 \mu \mathrm{m}$ (d). 

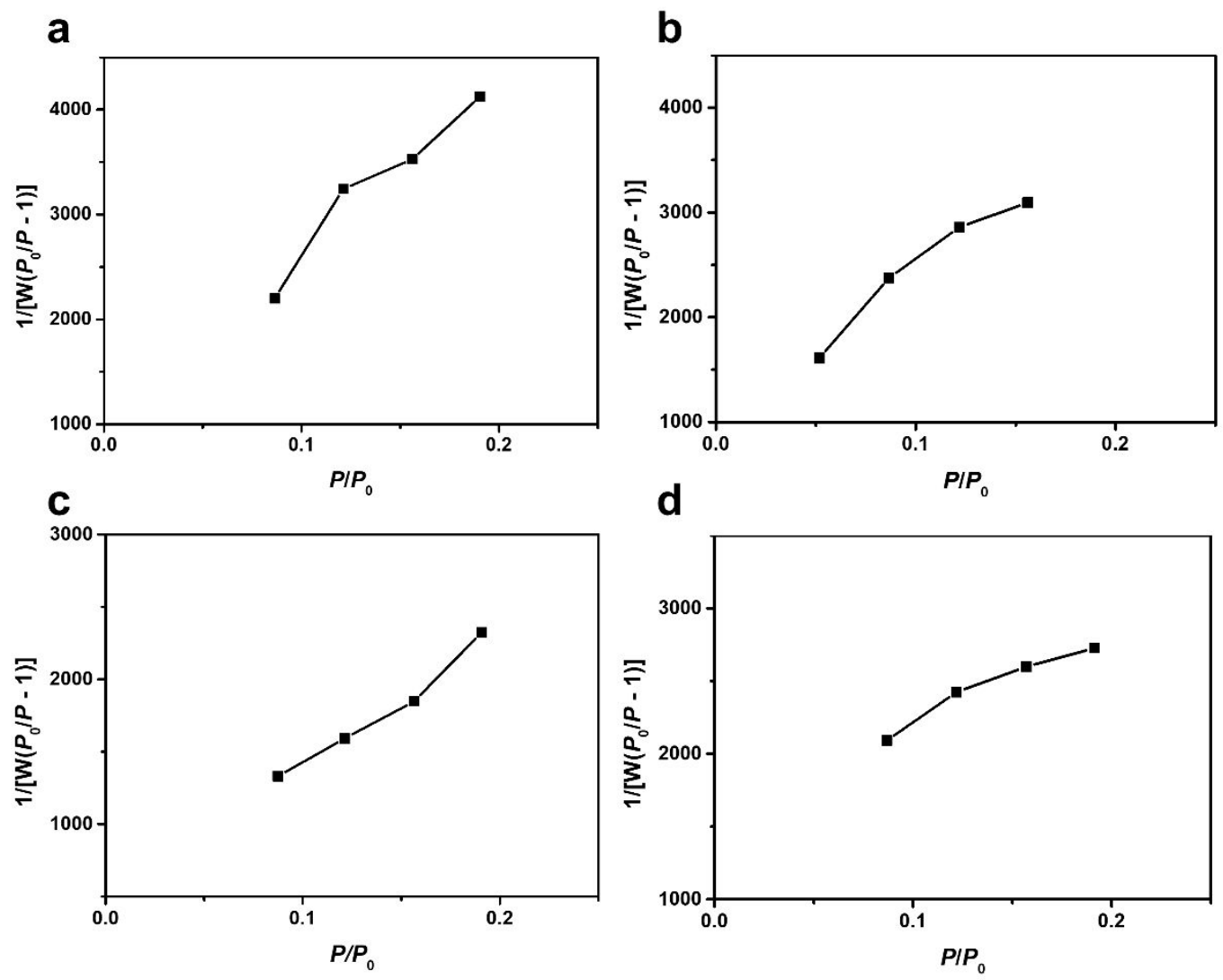

Figure S4. The BET plots for the foams with a filtration accuracy of $10 \mu \mathrm{m}$ (a), $20 \mu \mathrm{m}$ (b), $30 \mu \mathrm{m}$ (c) and $50 \mu \mathrm{m}$ (d). 


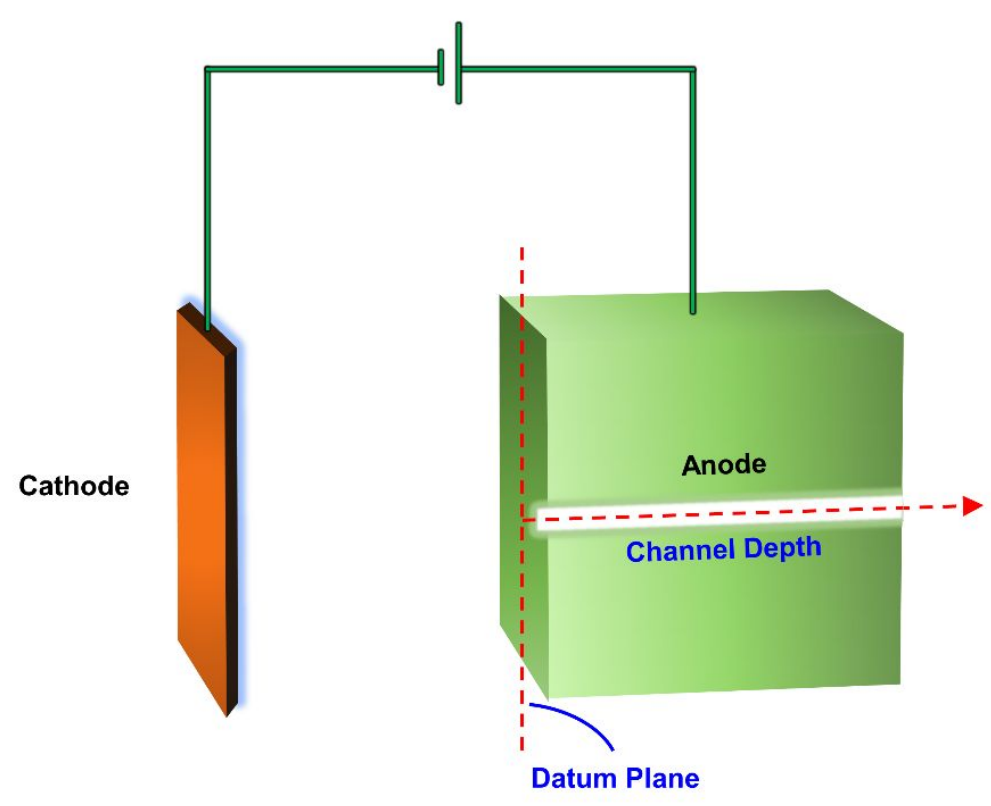

Figure S5. An illustration showing the experimental setup to coat the microchannels with $\mathrm{TiO}_{2}$ nanotubes, with $\mathrm{Ti}$ foam (Anode) surface facing the cathode being the datum plane to indicate the channel depth. 


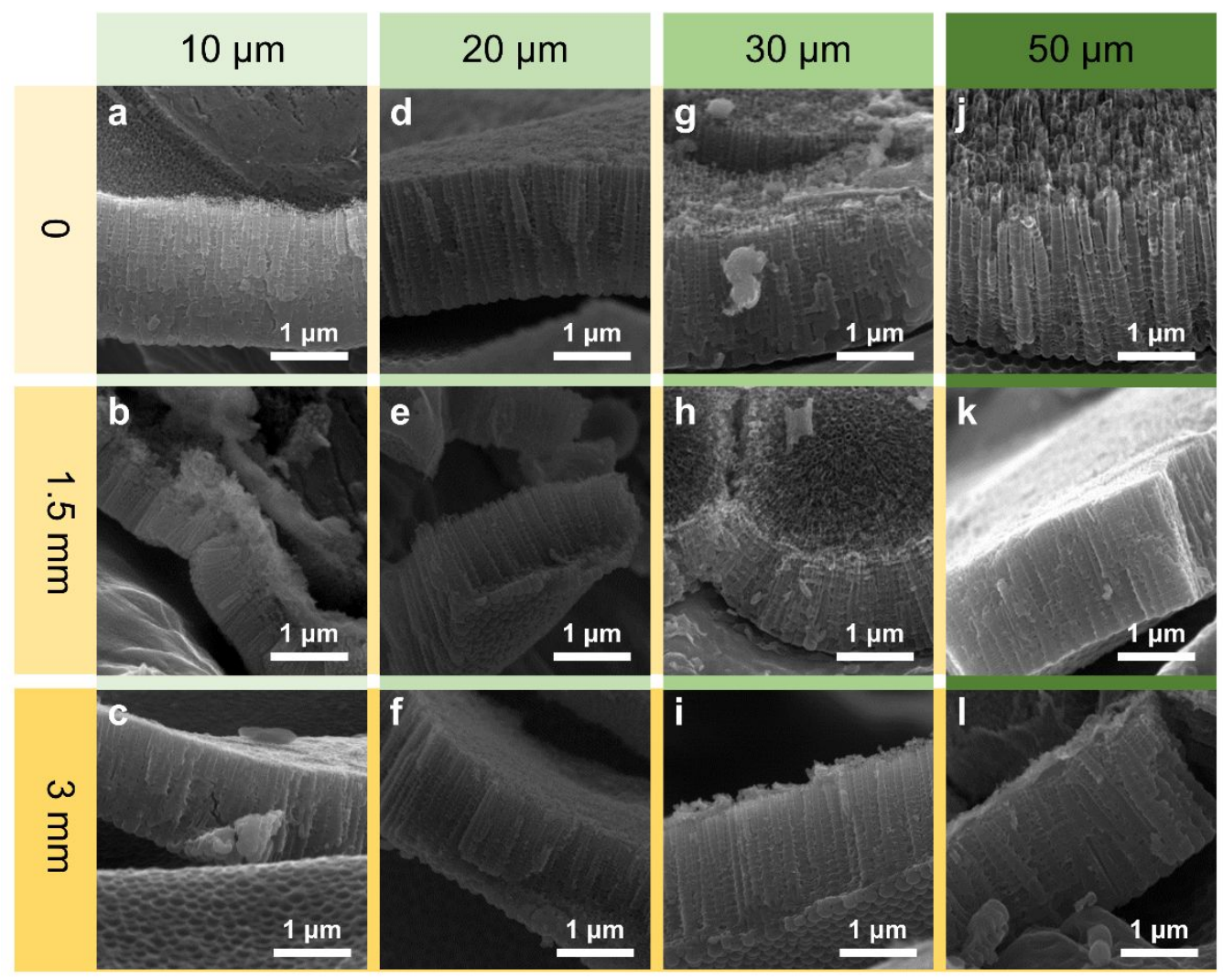

Figure S6. Typical cross-sectional FESEM images of $\mathrm{TiO}_{2}$ nanotubes grown on porous

Ti foams with a filtration accuracy of about $10 \mu \mathrm{m}(\mathrm{a}-\mathrm{c}), 20 \mu \mathrm{m}(\mathrm{d}-\mathrm{f}), 30 \mu \mathrm{m}(\mathrm{g}-\mathrm{i})$ and $50 \mu \mathrm{m}(\mathrm{j}-1)$ at a channel depth of $0 \mathrm{~mm}(\mathrm{a}, \mathrm{d}, \mathrm{g}, \mathrm{j}), 1.5 \mathrm{~mm}(\mathrm{~b}, \mathrm{e}, \mathrm{h}, \mathrm{k})$ and $3 \mathrm{~mm}(\mathrm{c}, \mathrm{f}$, $\mathrm{i}, 1)$. 


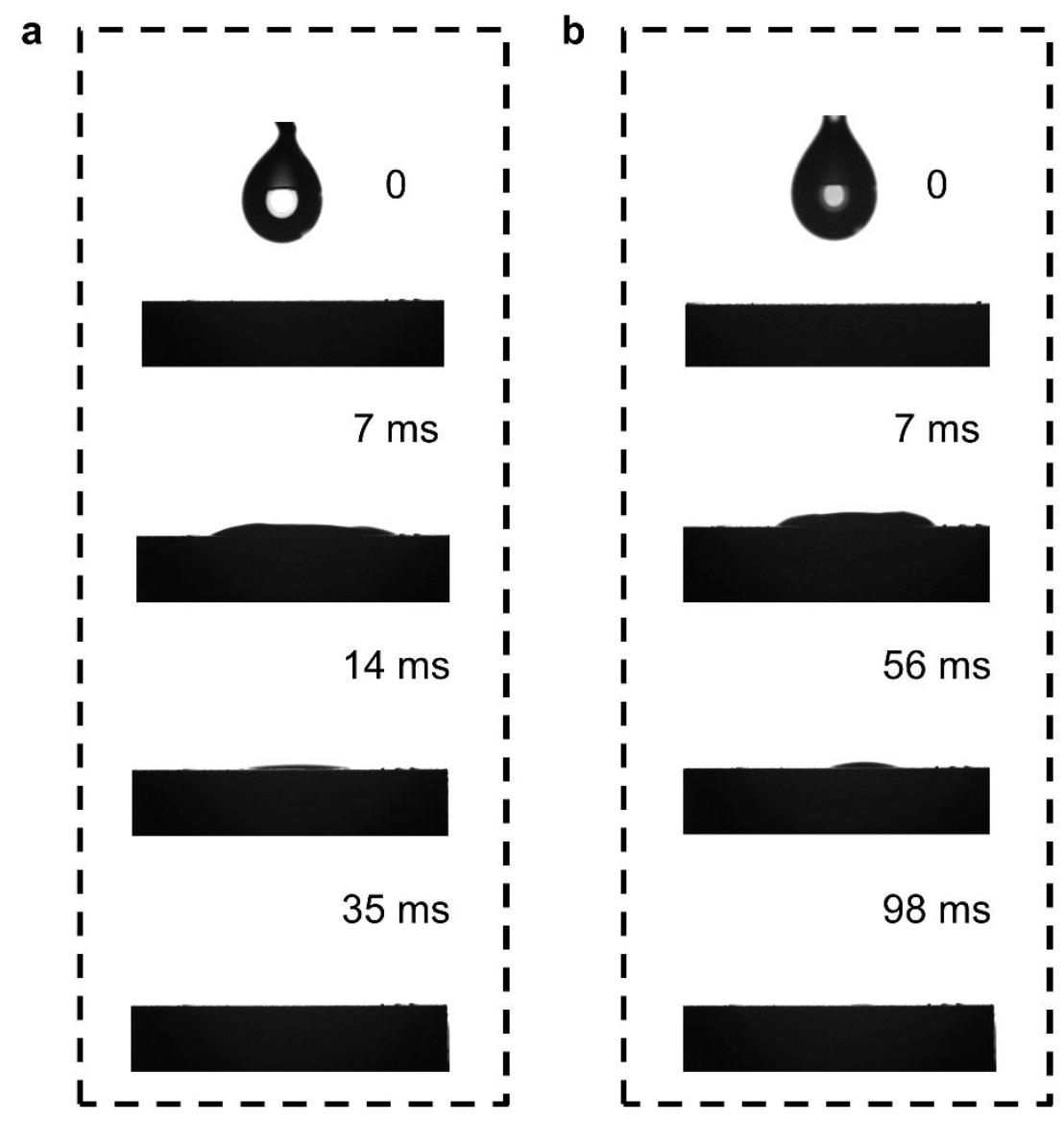

Figure S7. The infiltration evolution of water (a) and $n$-hexane (b) droplets on nanotube-coated titanium foams with an average channel size of $14 \mu \mathrm{m}$, captured from Video S1. 

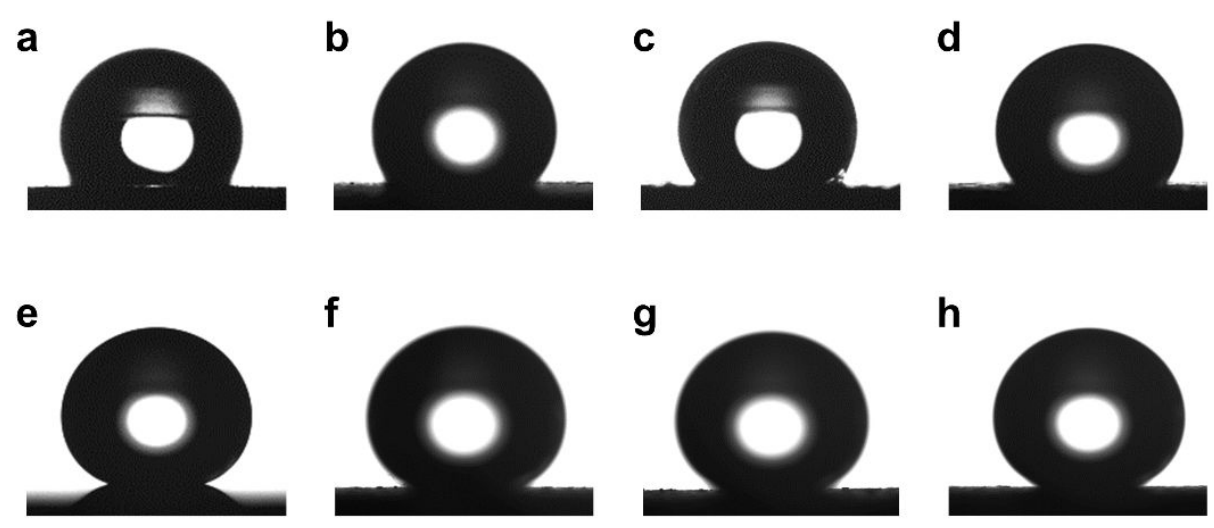

Figure S8. Water contact angle on the original $(a-d)$ and nanotube-coated/TPFStreated (e-h) foams with an average channel size of $14 \mu \mathrm{m}(\mathrm{a}, \mathrm{e}), 20 \mu \mathrm{m}(\mathrm{b}, \mathrm{f}), 33 \mu \mathrm{m}$ (c, g), and $55 \mu \mathrm{m}(\mathrm{d}, \mathrm{h})$. 
a

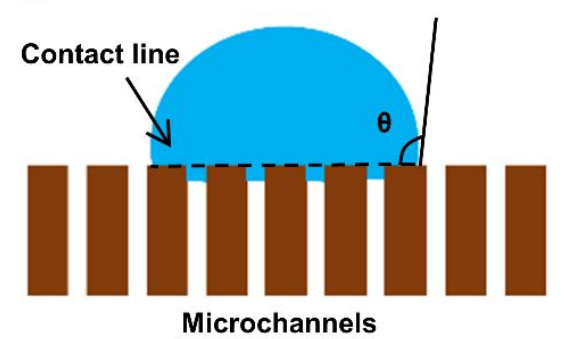

b

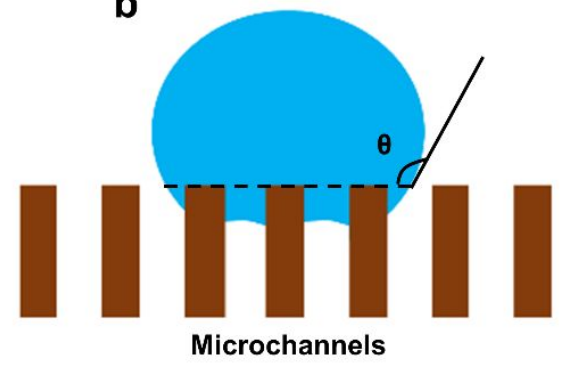

Figure S9. Schematics of a water droplet on titanium foams with small (a) and large

(b) channels to illustrate the contact angle changes. 

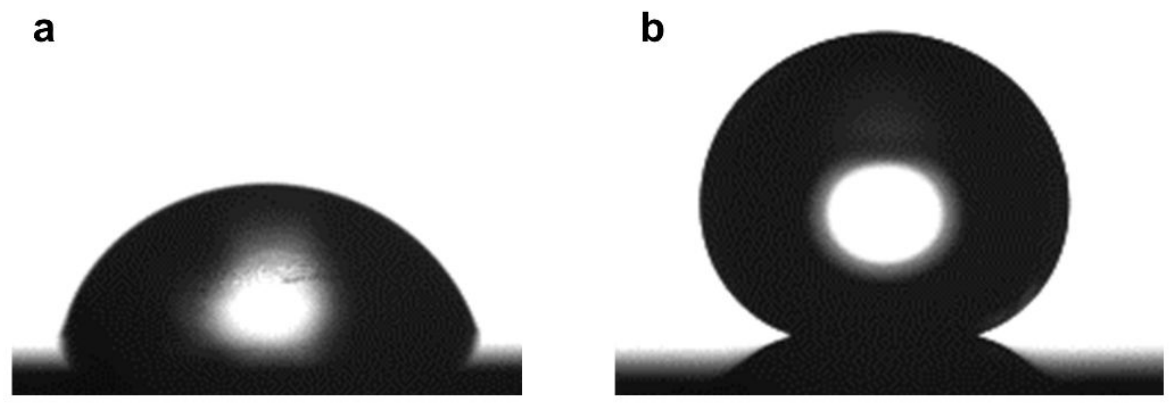

Figure S10. Water contact angle on an original (a) and corresponding TPFS-treated (b) titanium foil. 

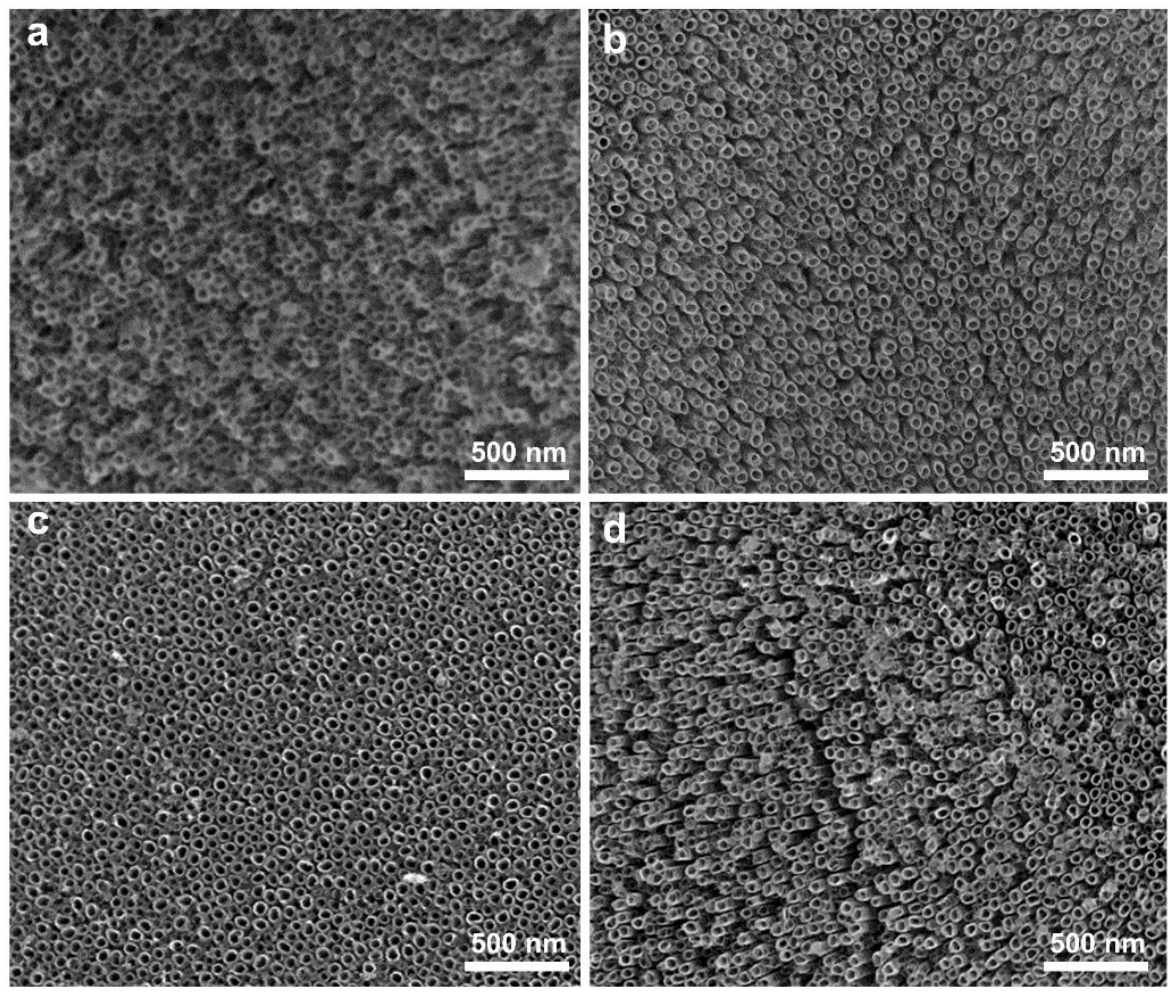

Figure S11. Top-view FESEM images of the nanotube arrays grown on foams of 14 $\mu \mathrm{m}$ (a), $20 \mu \mathrm{m}$ (b), $33 \mu \mathrm{m}$ (c) and $55 \mu \mathrm{m}$ (d) channel size. The morphologies are similar with an average surface porosity of $68 \%$ induced by the nanotube patterns. 
a

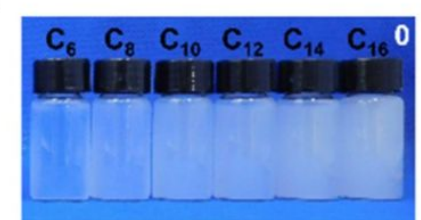

$1 \mathrm{~h}$

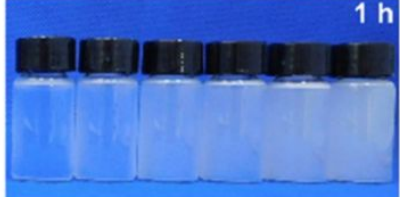

$2 \mathrm{~h}$

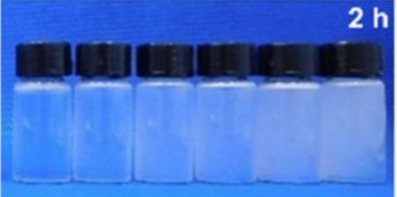

$3 \mathrm{~h}$

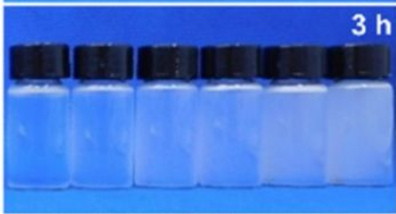

$8 \mathrm{~h}$

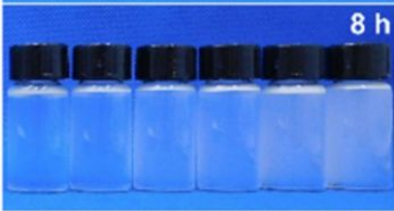

$16 \mathrm{~h}$

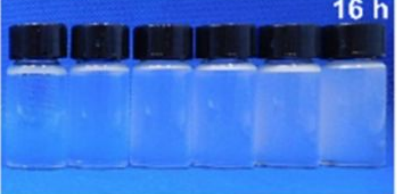

$24 \mathrm{~h}$

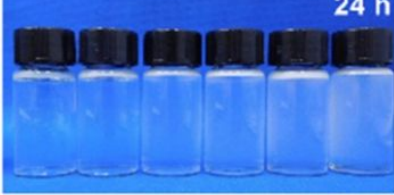

$32 \mathrm{~h}$

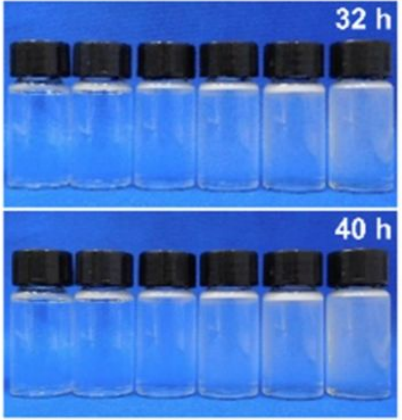

b
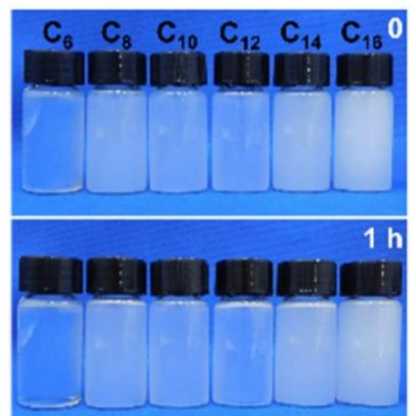

$2 \mathrm{~h}$

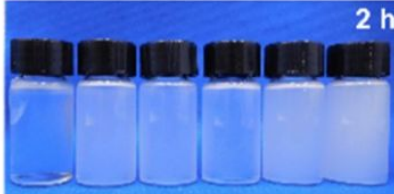

$3 \mathrm{~h}$

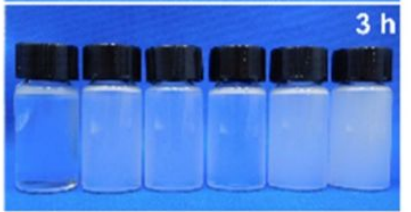

$8 \mathrm{~h}$

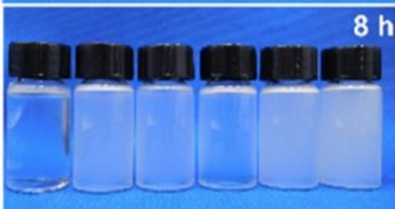

$16 \mathrm{~h}$

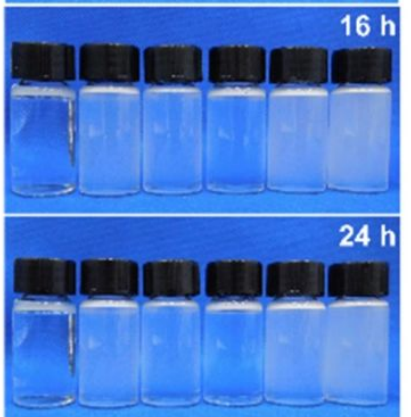

$32 \mathrm{~h}$

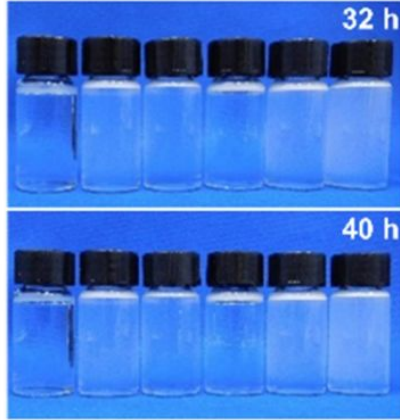

Figure S12. Stability comparison between surfactant-free (a) and SDS-stabilized (b, 1 $\mathrm{mg} / \mathrm{L}$ sodium dodecyl sulfate) emulsions at $28^{\circ} \mathrm{C}$. Note that $\mathrm{C}_{6}, \mathrm{C}_{8}, \mathrm{C}_{10}, \mathrm{C}_{12}, \mathrm{C}_{14}$ and $\mathrm{C}_{16}$ stands for $n$-hexane, $n$-octane, $n$-decane, $n$-dodecane, $n$-tetradecane and $n$ hexadecane, respectively. 


\section{The Method to Evaluate Emulsion Stability Based on Photographs}

The grayscale of a photograph generally ranges from 0 (i.e., the black color) to 255 (i.e., the white color) to quantitatively reflect the color scale. The extraction of grayscale information from the photographs has been widely used for quantitative analysis in the fields of biology and medicine $[1,2]$. In this study, the color of alkanein-water emulsions gradually fades from milky white to transparent with time. As such, the stability of the emulsion can be quantitatively estimated by the changes in grayscale of the photographs.

The grayscale of an RGB photograph can be obtained by the Image J software (v1.51j8), which automatically converts the RGB into grayscale. The $G_{\mathrm{A}}$ and $G_{\mathrm{B}}$ represent the grayscale of the emulsion and background zones, respectively, as shown in Figure S13. The background grayscale is used as the reference or baseline for each photograph. Accordingly, the relative grayscale of an emulsion is determined by the difference between $G_{\mathrm{A}}$ and $G_{\mathrm{B}}$, as follows

$$
G_{\mathrm{A}}^{\prime}=G_{\mathrm{A}}-G_{\mathrm{B}}
$$

The relative grayscale of an emulsion is then normalized to that of the $n$-hexane (i.e., Normalized Intensity) to compare the stability between different emulsions, as shown in Figure 4 of the main text. 


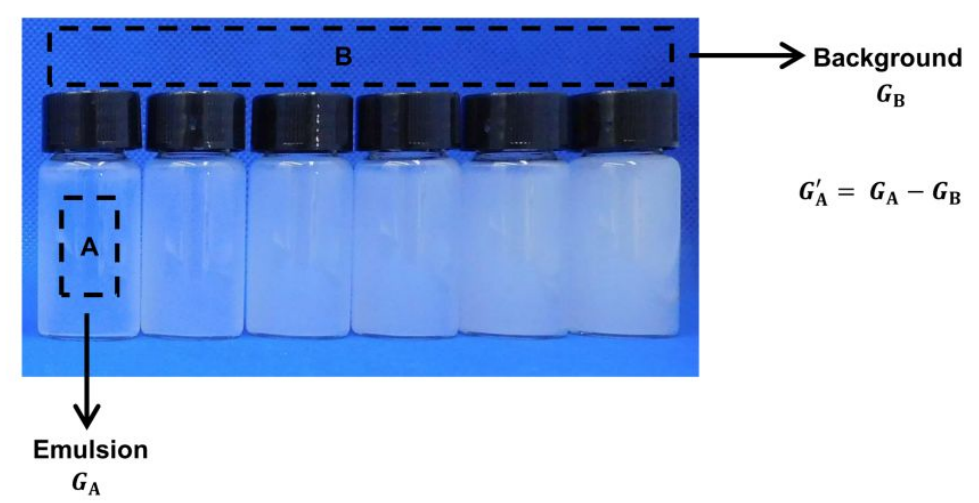

Figure S13. The measurement zone to determine the average grayscale (after converting the RGB into grayscale by ImageJ) of the alkane-in-water emulsions (i.e., $G_{\mathrm{A}}$ in zone A) and the background (i.e., $G_{\mathrm{B}}$ in zone B). The relative grayscale of an emulsion is determined by the difference between $G_{\mathrm{A}}$ and $G_{\mathrm{B}}$, i.e., $G_{\mathrm{A}}^{\prime}=G_{\mathrm{A}}-G_{\mathrm{B}}$. 


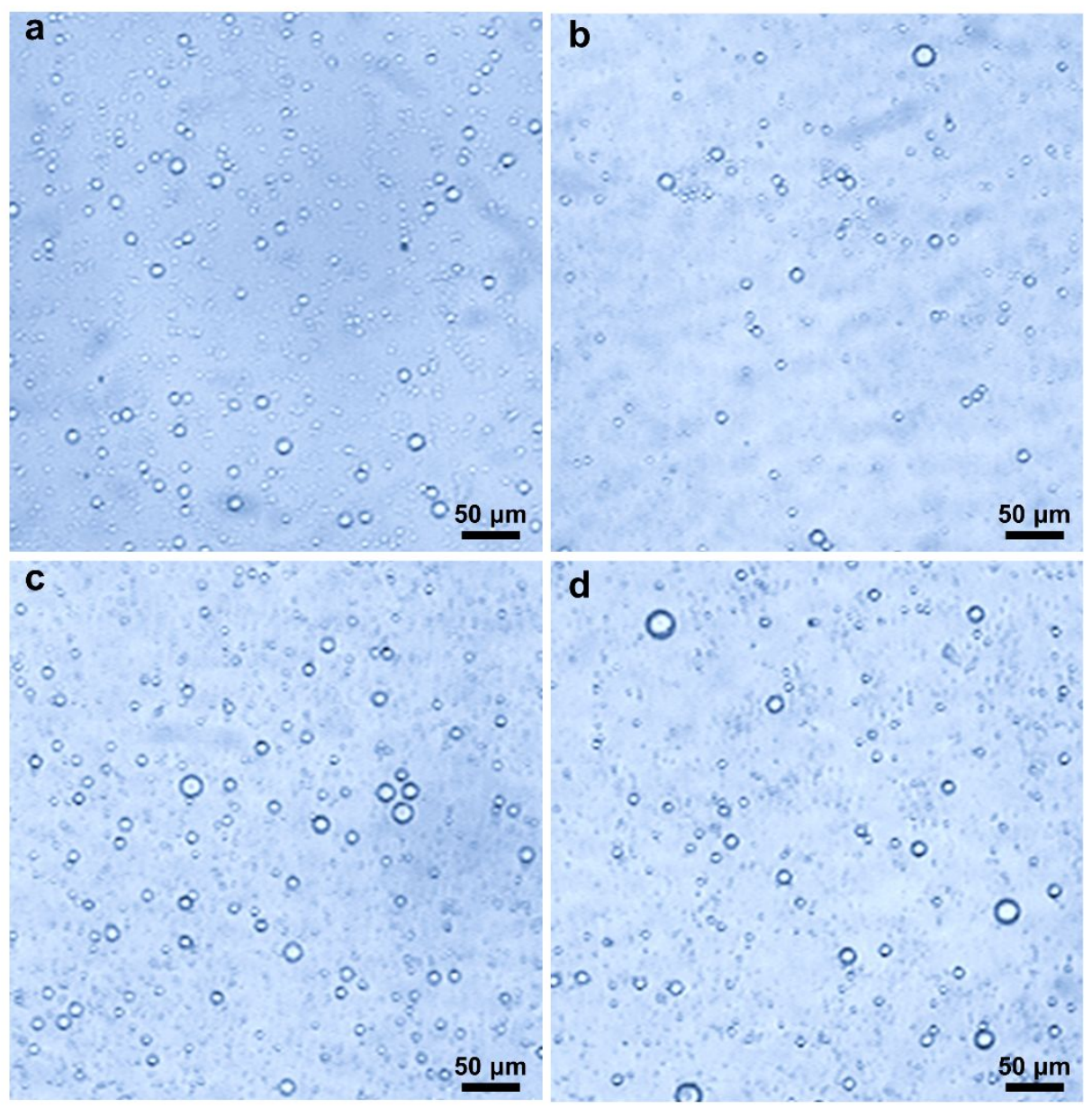

Figure S14. Optical microscopic images of $n$-hexane (a), $n$-octane (b), $n$-dodecane (c), and $n$-hexadecane (d) droplets in the emulsions at $20^{\circ} \mathrm{C}$. 

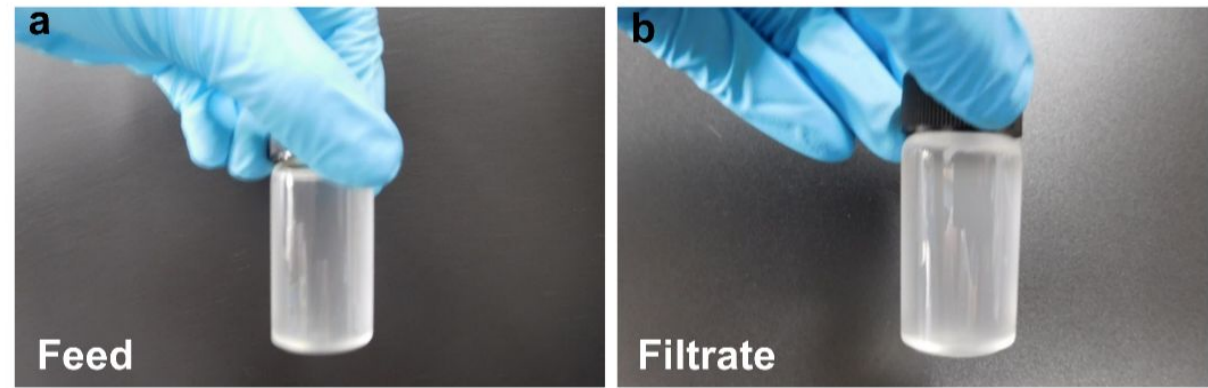

Figure S15. Photographs of the original $n$-hexane-in-water emulsion (a) and its filtrate

(b) separated by using the superwetting channels of $55 \mu \mathrm{m}$. 

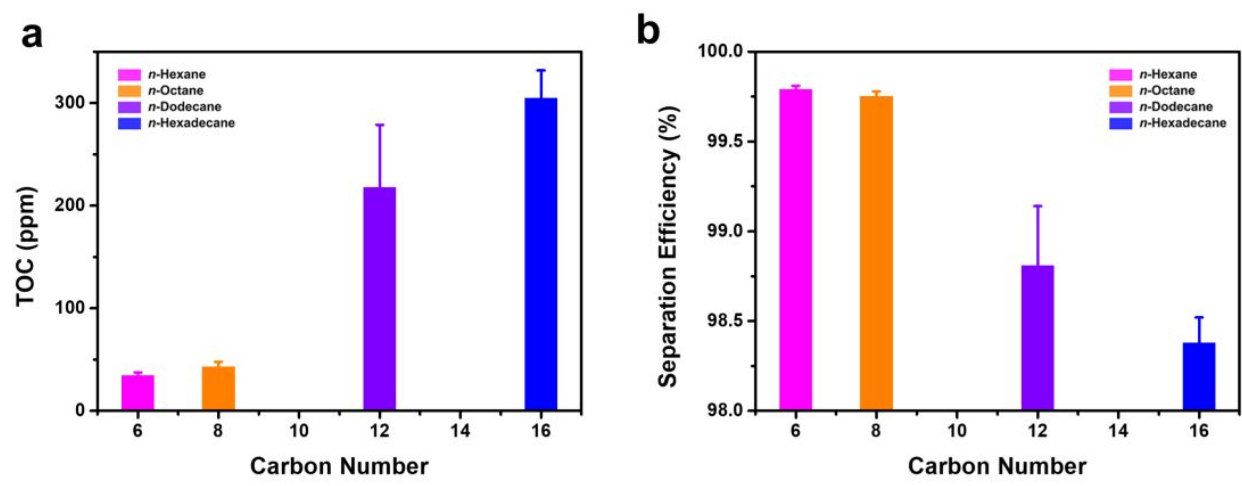

Figure S16. TOC content in the filtrates (a) and corresponding separation efficiency (b) of the SDS-stabilized emulsions using superwetting channels of $14 \mu \mathrm{m}$. 


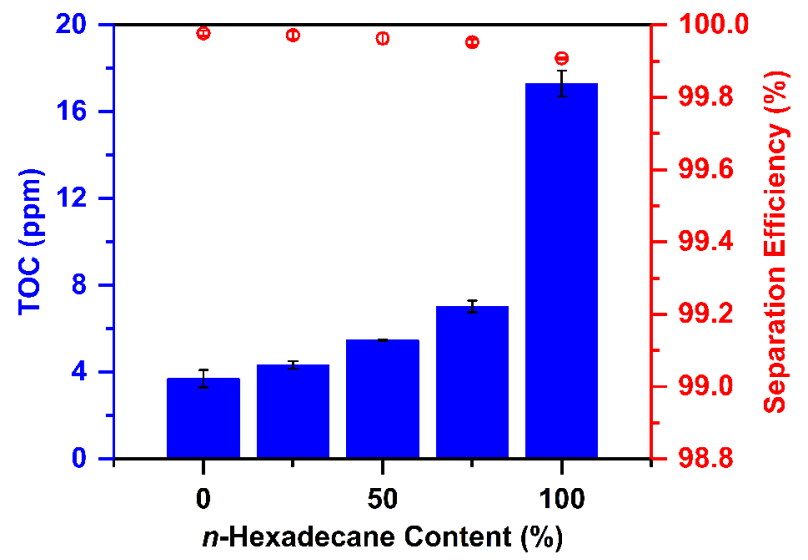

Figure S17. The TOC value and separation efficiency as a function of $n$-hexadecane content in the mixed emulsion system of $n$-hexane and $n$-hexadecane with different volume ratios, separated by using the superhydrophilic microchannels of $14 \mu \mathrm{m}$. 


\section{The Simulation Methods}

The level set can be used to capture the interface movement of two-phase system $[3,4]$. In the simulation, the level set traces the fluid interface by capturing the isolines of the level set function, $\phi$. The governing equation is:

$$
\frac{\partial \phi}{\partial t}+\nabla(\phi v)=\gamma \nabla \cdot\left(\varepsilon \nabla \phi-\phi(1-\phi) \frac{\nabla \phi}{|\nabla \phi|}\right)
$$

where $v$ is the fluid velocity, $\varepsilon$ is the interface thickness parameter $(\varepsilon=2.5 \mu \mathrm{m}$ in the simulation), $\gamma$ is the reinitialization parameter $\left(\gamma=0.25 \mathrm{~m} \mathrm{~s}^{-1}\right.$ in the simulation).

The $\phi$ is used to calculate the density and dynamic viscosity by

$$
\rho=\rho_{\mathrm{W}}+\left(\rho_{\mathrm{O}}-\rho_{\mathrm{W}}\right) \phi
$$

and

$$
\mu=\mu_{\mathrm{W}}+\left(\mu_{\mathrm{O}}-\mu_{\mathrm{W}}\right) \phi
$$

where $\rho_{\mathrm{w}}, \rho_{\mathrm{o}}$ and $\mu_{\mathrm{w}}, \mu_{\mathrm{o}}$ are the constant density and viscosity of water and oil, respectively. The following parameters are used in the simulation, $\rho_{\mathrm{w}}=1000 \mathrm{Kg} \mathrm{m}^{-3}$,

$\mu_{\mathrm{w}}=1.0 \times 10^{-3} \mathrm{~Pa} \cdot \mathrm{s}, \rho_{n \text {-Hexane }}=659 \mathrm{Kg} \mathrm{m}^{-3}, \mu_{n \text {-Hexane }}=0.30 \times 10^{-3} \mathrm{~Pa} \cdot \mathrm{s}, \rho_{n \text {-Octane }}=708$ $\mathrm{Kg} \mathrm{m}^{-3}, \mu_{n \text {-Octane }}=0.46 \times 10^{-3} \mathrm{~Pa} \cdot \mathrm{s}, \rho_{n \text {-Dodecane }}=753 \mathrm{Kg} \mathrm{m}^{-3}, \mu_{n \text {-Dodecane }}=1.48 \times 10^{-3}$ $\mathrm{Pa} \cdot \mathrm{s}, \rho_{n \text {-Hexadecane }}=774 \mathrm{Kg} \mathrm{m}^{-3}, \mu_{n \text {-Hexadecane }}=3.51 \times 10^{-3} \mathrm{~Pa} \cdot \mathrm{s}$.

The transport of mass and momentum is governed by the incompressible Navier-

Stokes equations:

$$
\begin{array}{r}
\rho\left(\frac{\partial v}{\partial t}+v \cdot \nabla v\right)=-\nabla p+\nabla \cdot\left(\nabla v+\nabla v^{T}\right)+\rho g+F_{\mathrm{st}} \\
\nabla \cdot v=0
\end{array}
$$

where $p$ is the pressure, $F_{\text {st }}$ is the surface tension force components: 


$$
F_{\mathrm{st}}=\nabla \cdot T=\nabla \cdot\left[\sigma\left\{I+\left(-n n^{T}\right)\right\} \delta\right]
$$

where $\sigma$ is the surface tension coefficient ( $\sigma=0.031 \mathrm{~N} \mathrm{~m}^{-1}$ in the simulation), $I$ is the identity matrix, $n$ is the interface unit normal, and $\delta$ is a Dirac delta function, nonzero only at the fluid interface. The $n$ is computed from

$$
n=\frac{\nabla \phi}{|\nabla \phi|}
$$

The $\phi$ is also used to approximate the delta function by a smooth function defined by

$$
\delta=6|\phi(1-\phi)| \nabla \phi||
$$

Figure S18 displays the finite element models and corresponding mesh diagrams of different conditions. In the models, the blue and gray area is oil and water phase, respectively. At $t=0$, the velocity is zero. Under no slip conditions, set $v=0$ at the top and bottom, and wetted wall condition $\left(\theta_{\mathrm{w}}=90^{\circ}\right)$ on the left and right boundary. Twophase interfaces are set as the initial interfaces, and the left and right points of the oil droplets are set as the pressure constraints $\left(p_{0}=0 \mathrm{~Pa}\right)$. 


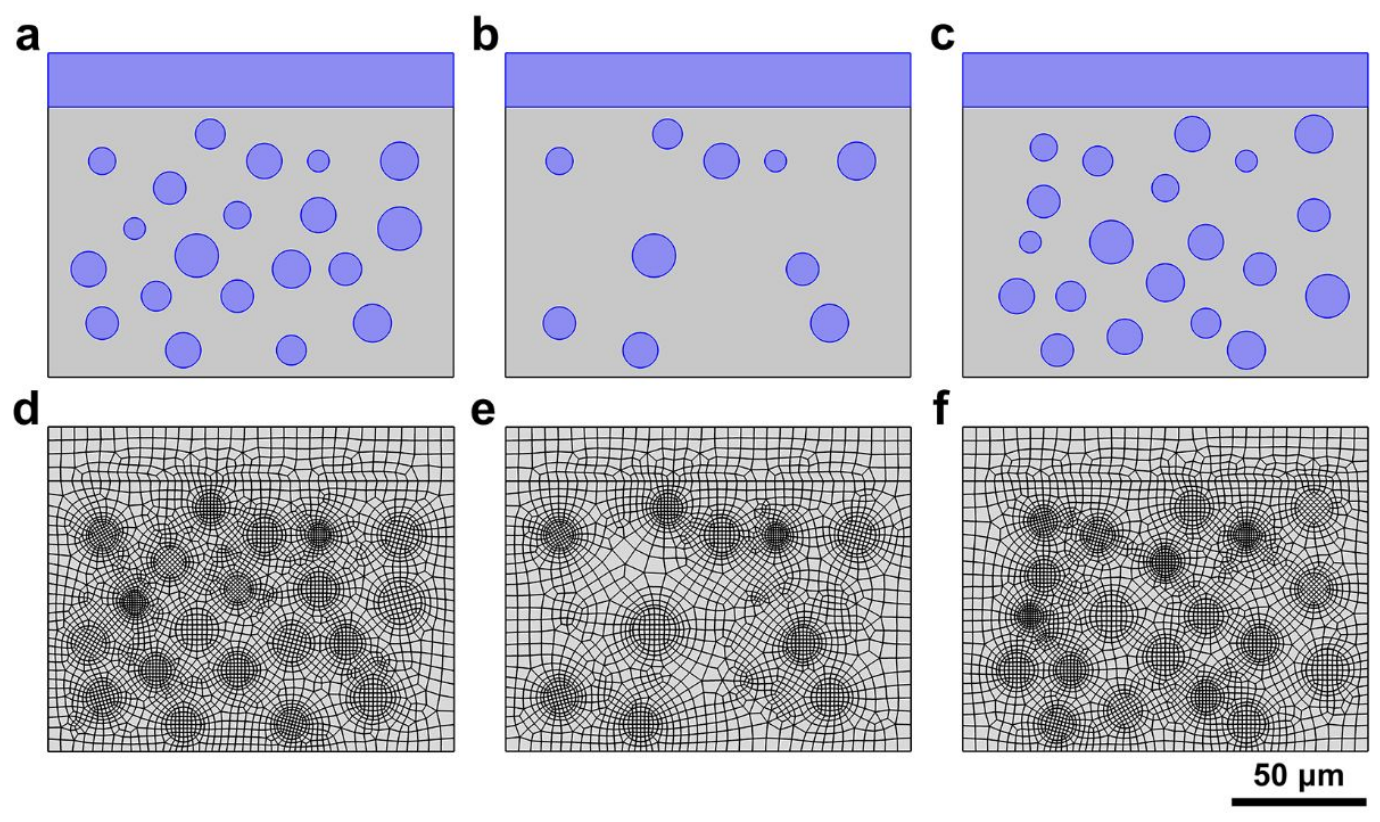

Figure S18. Two-dimensional finite element models $(\mathrm{a}-\mathrm{c})$ and corresponding mesh diagrams $(d-f)$ of the major model used in Figure 8 of the main text $(a, d)$, and that with reduced oil concentration (b, e) and with randomly changed oil position (c, f). 


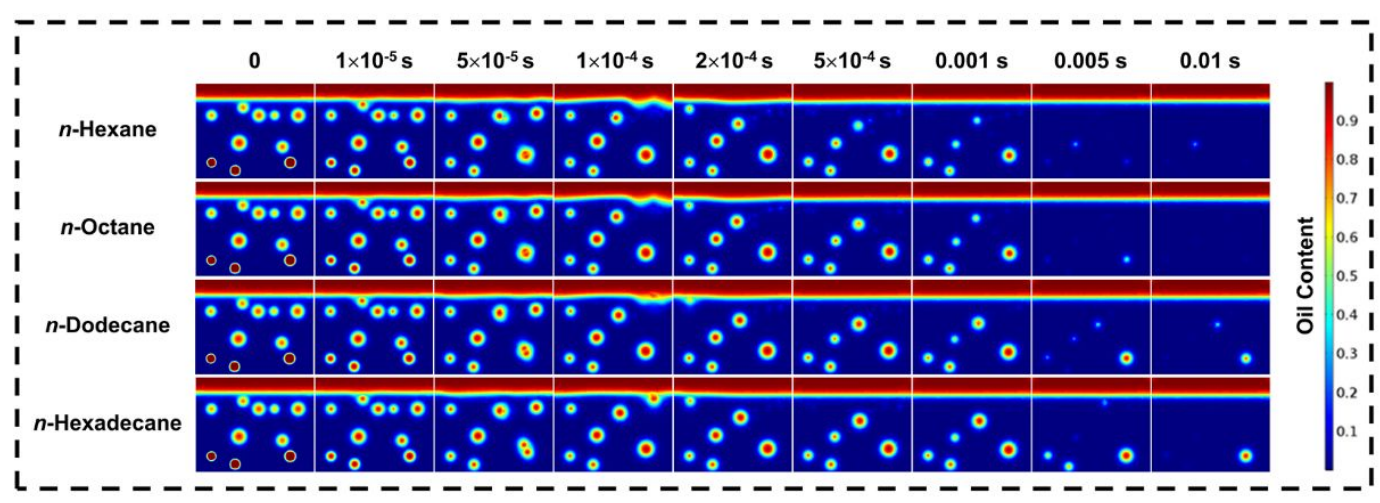

Figure S19. The finite element simulation results with the droplet concentration being half-reduced as compared to the major model in Figure 8 of the main text. 


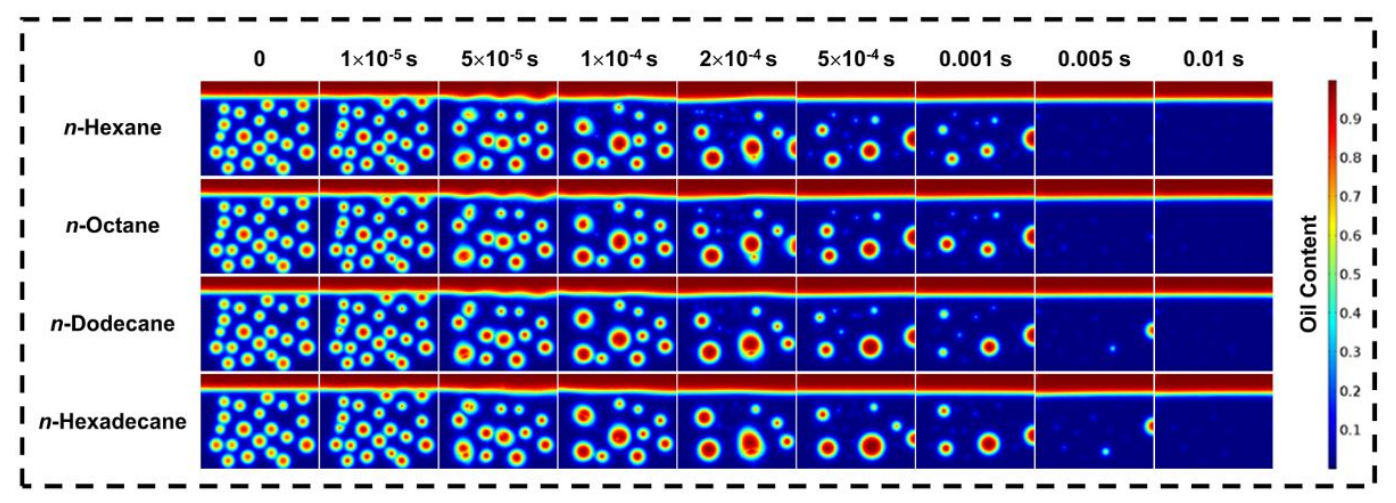

Figure S20. The finite element simulation results with the droplet initial position being randomly-changed as compared to the major model in Figure 8 of the main text. 


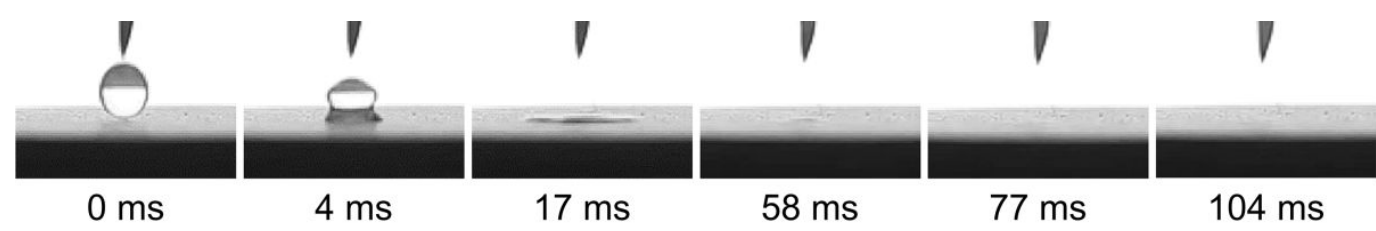

Figure S21. The typical infiltration evolution of $n$-hexane droplets on original titanium foams with an average channel size of $14 \mu \mathrm{m}$. 


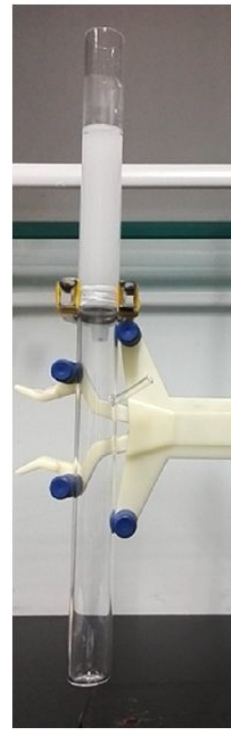

0

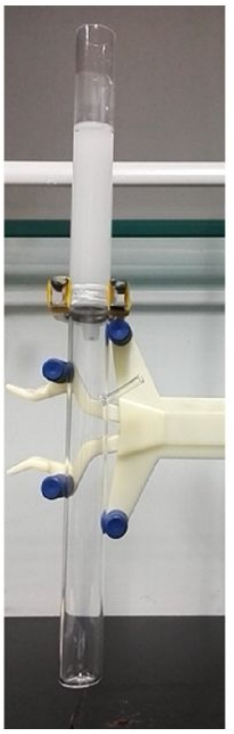

5 min

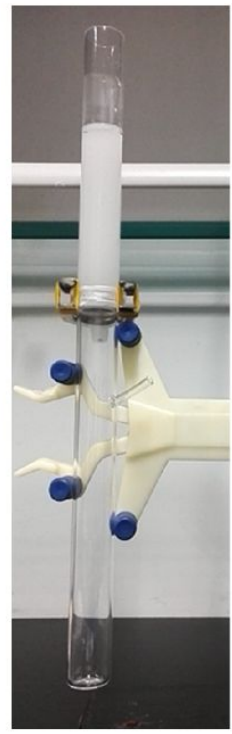

$10 \mathrm{~min}$

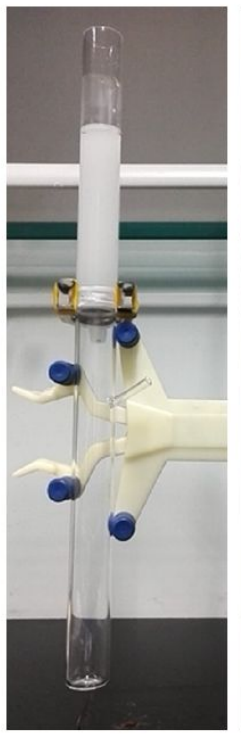

$20 \mathrm{~min}$

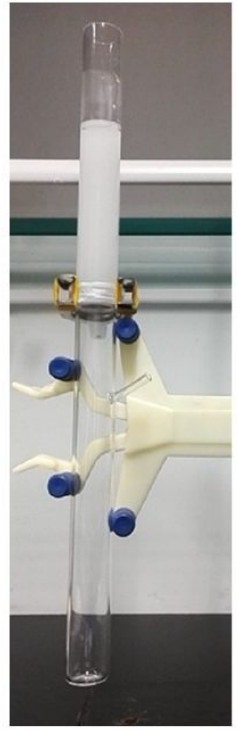

$40 \mathrm{~min}$

Figure S22. The emulsion separation using superhydrophobic foams at $20{ }^{\circ} \mathrm{C}$, where the $n$-hexadecane-in-water emulsion fails to pass through the channels of $14 \mu \mathrm{m}$. 

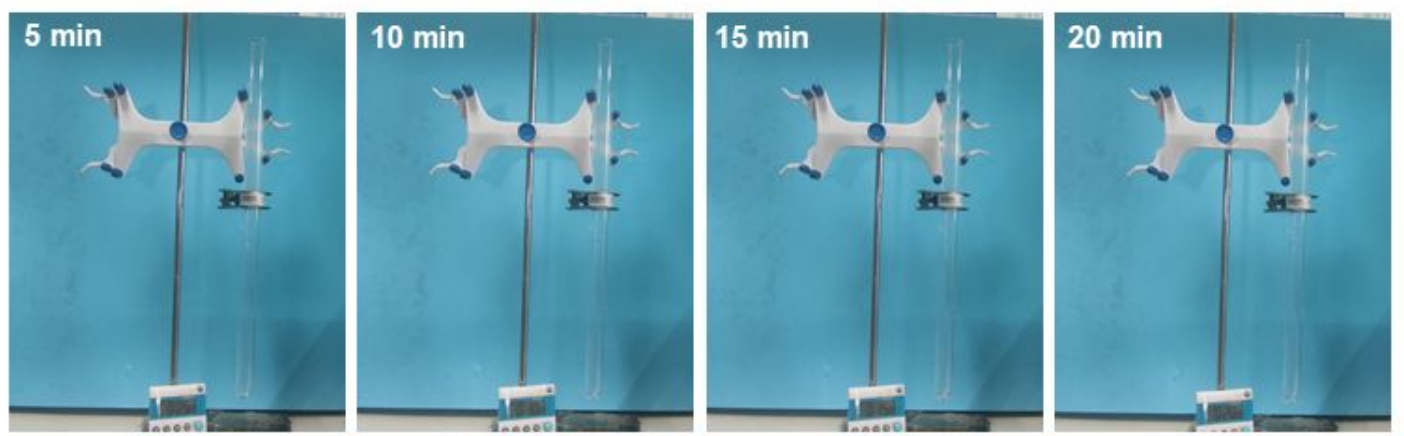

Figure S23. The emulsion separation using original foams at $20^{\circ} \mathrm{C}$, where the $n$ hexane-in-water emulsion fails to pass through the channels of $14 \mu \mathrm{m}$. 
a

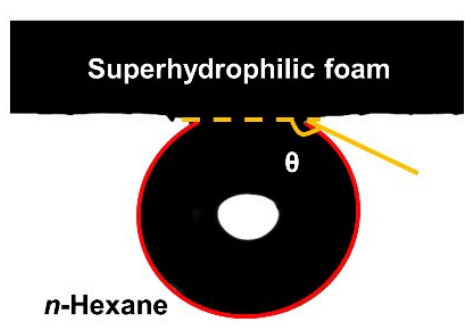

Water

b

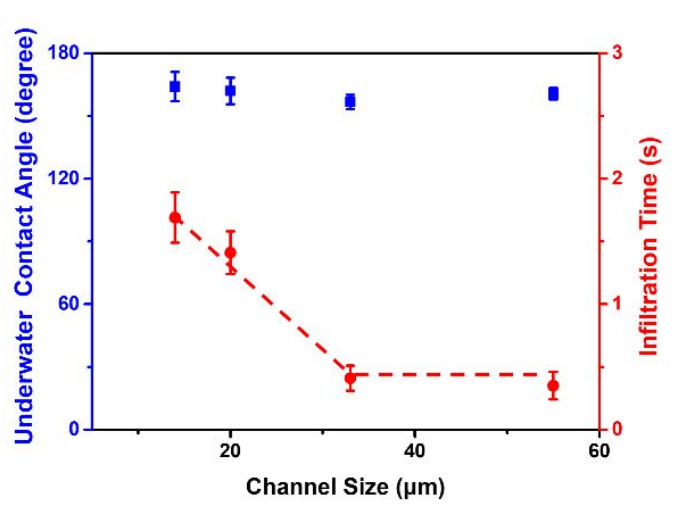

C

0

0

Original

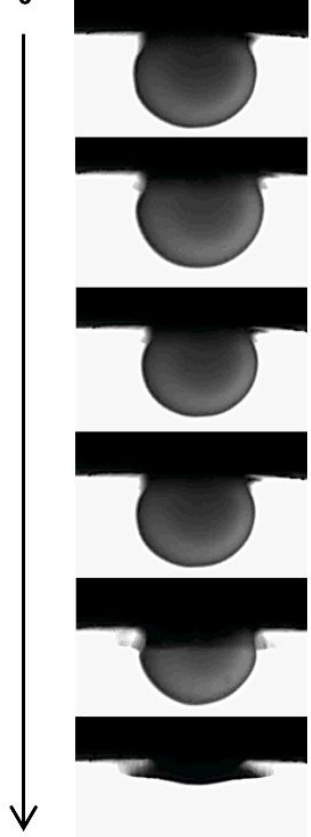

$2.10 \mathrm{~s}$
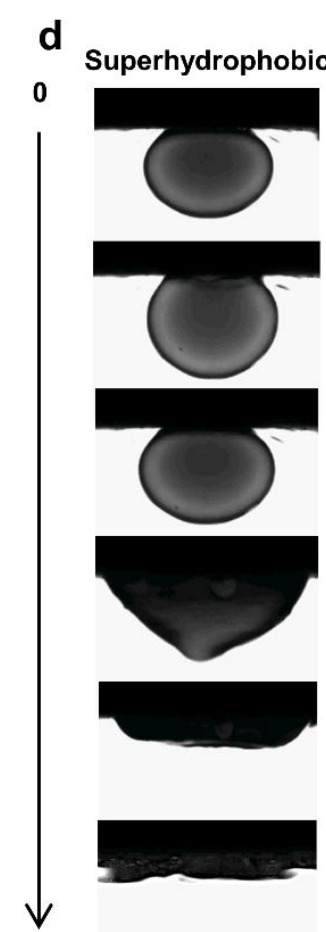

e
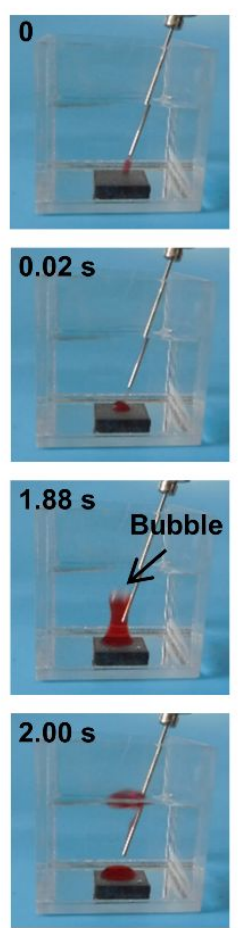

$\mathbf{f}$
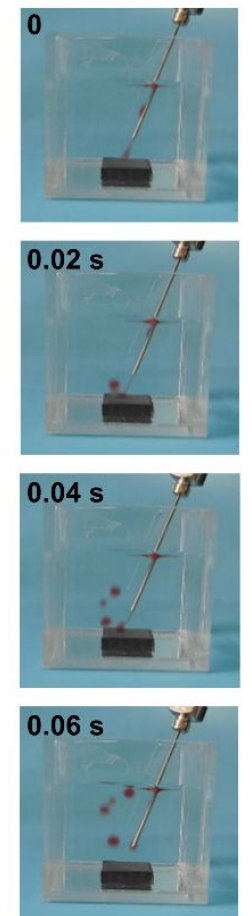

Figure S24. Underwater Superoleophobicity. A typical photograph (a) and statistical results (b) of underwater contact angle on superhydrophilic foams with different channel sizes, and the infiltration time of the droplet on original foams is also given in (b), measured by the setup in Figure S26. The droplet evolution on the original (c) and superhydrophobic (d) foams. The collision of the $n$-hexane jet on the original (e) and superhydrophilic (f) foams. Foam configuration: $14 \mu \mathrm{m}$ channel size unless indicated; Droplet type: $n$-hexane. 


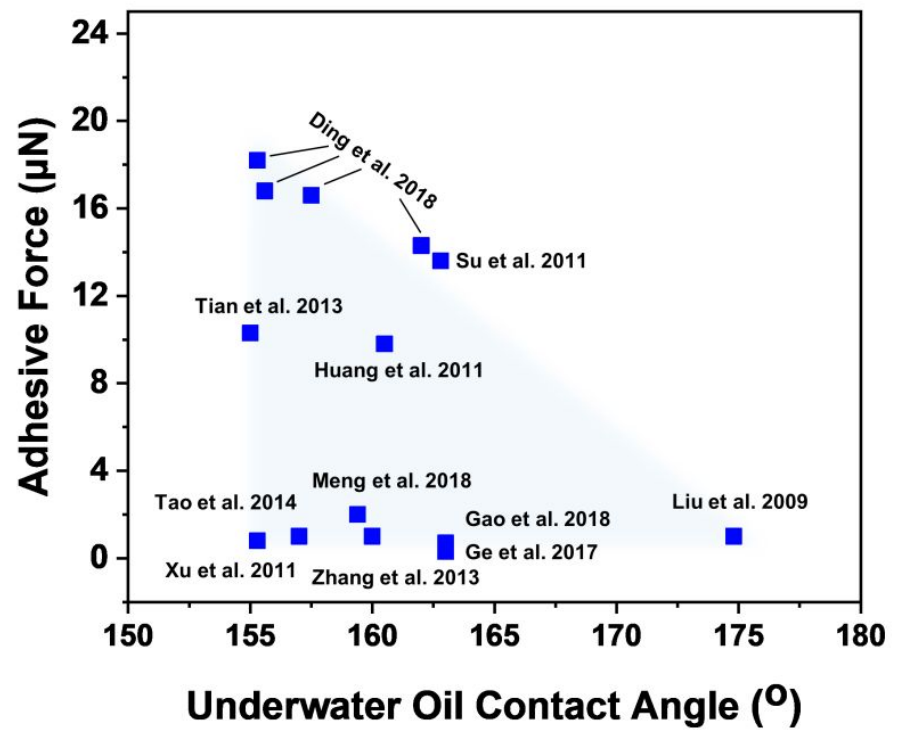

Figure S25. Statistics on the adhesive force of hydrocarbon oil droplets on superhydrophilic surfaces under water. Data are based on the previous reports elsewhere (Huang et al. Adv. Funct. Mater. 2011, 21, 4436-4441; Su et al. Soft Matter 2011, 7, 5144-5149; Ding et al. Adv. Funct. Mater. 2018, 28, 1706686; Zhang et al. Adv. Funct. Mater. 2013, 25, 4192-4198; Liu et al. Adv. Mater. 2009, 21, 665-669; Tian et al. Adv. Funct. Mater. 2013, 24, 536-542; Xu et al. Adv. Mater. 2011, 23, 42704273; Tao et al. Adv. Mater. 2014, 26, 2943-2948; Gao et al. Adv. Funct. Mater. 2018, 28, 1801944; Meng et al. Adv. Mater. 2018, 30, 1706634; Ge et al. J. Mater. Chem. A 2017, 5, 497-502). 


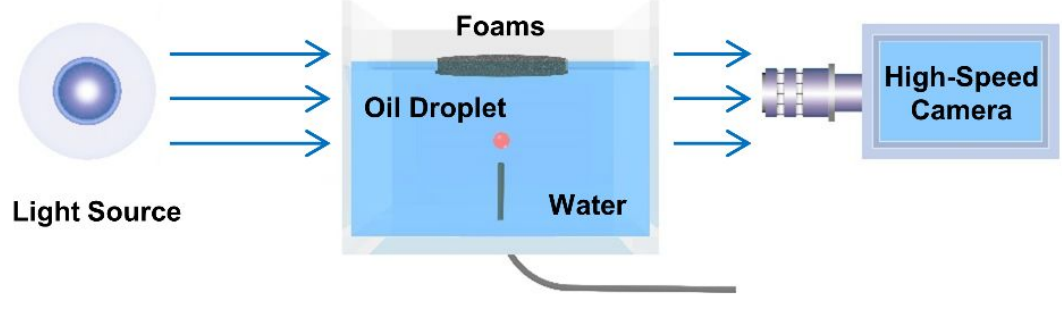

Stainless Steel Capillary

Figure S26. Experimental setup for underwater contact angle measurement, where the underwater oil droplet evolution on foams can be recorded using a high-speed camera. 
Table S1. Physical parameters of porous titanium foam

\begin{tabular}{|c|c|c|c|}
\hline $\begin{array}{c}\text { Filtration } \\
\text { Accuracy }(\mu \mathrm{m})\end{array}$ & $\begin{array}{c}\text { Average Channel } \\
\text { Size }(\mu \mathrm{m})^{\mathrm{a}}\end{array}$ & Porosity $(\%)^{\mathrm{a}}$ & $\begin{array}{c}\text { Specific Surface } \\
\text { Area }\left(\mathrm{m}^{2} / \mathrm{g}\right)^{\mathrm{b}}\end{array}$ \\
\hline 10 & $14 \pm 10$ & 26 & $0.192 \pm 0.003$ \\
\hline 20 & $20 \pm 11$ & 32 & $0.232 \pm 0.004$ \\
\hline 30 & $33 \pm 18$ & 37 & $0.396 \pm 0.023$ \\
\hline 50 & $55 \pm 25$ & 43 & $0.467 \pm 0.011$ \\
\hline
\end{tabular}

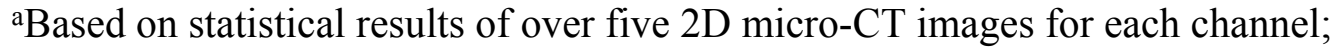
${ }^{b}$ Based on BET results. 
Table S2. Physical properties of common $n$-alkanes

\begin{tabular}{|c|c|c|c|}
\hline Alkane & Formula & $\begin{array}{c}\text { Freezing Point } \\
\left({ }^{\circ} \mathrm{C}\right)\end{array}$ & Boiling Point $\left({ }^{\circ} \mathrm{C}\right)$ \\
\hline$n$-Pentane & $\mathrm{C}_{5} \mathrm{H}_{12}$ & $-129.75^{\mathrm{a}}$ & $35.28^{\mathrm{d}}$ \\
\hline$n$-Hexane & $\mathrm{C}_{6} \mathrm{H}_{14}$ & $-95.3^{\mathrm{b}}$ & $66.63^{\mathrm{d}}$ \\
\hline$n$-Heptane & $\mathrm{C}_{7} \mathrm{H}_{16}$ & $-90.66^{\mathrm{a}}$ & $95.46^{\mathrm{d}}$ \\
\hline$n$-Octane & $\mathrm{C}_{8} \mathrm{H}_{18}$ & $-56.89^{\mathrm{a}}$ & $122.30^{\mathrm{d}}$ \\
\hline$n$-Nonane & $\mathrm{C}_{9} \mathrm{H}_{20}$ & $-53.54^{\mathrm{a}}$ & $147.5^{\mathrm{d}}$ \\
\hline$n$-Decane & $\mathrm{C}_{10} \mathrm{H}_{22}$ & $-29.7^{\mathrm{b}}$ & $171.34^{\mathrm{d}}$ \\
\hline$n$-Undecane & $\mathrm{C}_{11} \mathrm{H}_{24}$ & $-25.61^{\mathrm{a}}$ & $194.02^{\mathrm{d}}$ \\
\hline$n$-Dodecane & $\mathrm{C}_{12} \mathrm{H}_{26}$ & $-9.6^{\mathrm{b}}$ & $215.68^{\mathrm{d}}$ \\
\hline$n$-Tridecane & $\mathrm{C}_{13} \mathrm{H}_{28}$ & $-5.42^{\mathrm{a}}$ & $236.46^{\mathrm{d}}$ \\
\hline$n$-Tetradecane & $\mathrm{C}_{14} \mathrm{H}_{30}$ & $5.9^{\mathrm{b}}$ & $256.45^{\mathrm{d}}$ \\
\hline$n$-Pentadecane & $\mathrm{C}_{15} \mathrm{H}_{32}$ & $9.8^{\mathrm{c}}$ & $275.75^{\mathrm{d}}$ \\
\hline$n$-Hexadecane & $\mathrm{C}_{16} \mathrm{H}_{34}$ & $18.2^{\mathrm{b}}$ & $294.41^{\mathrm{d}}$ \\
\hline$n$-Heptadecane & $\mathrm{C}_{17} \mathrm{H}_{36}$ & $21.95^{\mathrm{a}}$ & $312.49^{\mathrm{d}}$ \\
\hline
\end{tabular}

aFrom Reference [5];

bFrom Reference [6];

'From Reference [7];

${ }^{\mathrm{d}}$ From References [8] and [9]. 
Table S3. The full width at half maximum (FWHM) of the Gaussian fitting curves

\begin{tabular}{|c|c|}
\hline Alkane-in-Water Emulsions & FWHM $(\mu \mathrm{m})$ \\
\hline$n$-Hexane & 3.88 \\
\hline$n$-Octane & 4.02 \\
\hline$n$-Dodecane & 4.44 \\
\hline$n$-Hexadecane & 4.57 \\
\hline
\end{tabular}


Table S4. The TOC values of original emulsions

\begin{tabular}{|c|c|}
\hline Alkane-in-Water Emulsions & TOC $(\mathrm{ppm})$ \\
\hline$n$-Hexane & 16323 \\
\hline$n$-Octane & 17392 \\
\hline$n$-Dodecane & 18374 \\
\hline$n$-Hexadecane & 18968 \\
\hline
\end{tabular}




\section{REFERENCES}

1. Z. Zou, X. Hu, T. Luo et al. Nat. Commun., 2021, 12, 2263.

2. O. Schwartz and E. Simoncelli. Nat. Neurosci., 2001, 4, 819-825.

3. Y. Kagawa, T. Ishigami, K. Hayashi, H. Fuse, Y. Mino, H. Matsuyama, Soft Matter, 2014, 10, 7985-7992.

4. V. Vivacqua, M. Ghadiri, A. M. Abdullah, A. Hassanpour, M. J. Al-Marri, B. Azzopardi, B. Hewakandamby, B. Kermani, Chem. Eng. Res. Des., 2016, 114, 180 189.

5. A. K. Doolittle and R. H. Peterson. J. Am. Chem. Soc., 1951, 73, 2145-2151.

6. C. M. L. Atkinson and M. J. Richardson. Trans. Faraday Soc., 1969, 65, 1749-1763.

7. T. N. Veretennikova, B. A. Englin, V. G. Nikolaeva and T. N. Mitusova. Chem. Tech. Fuels Oil, 1980, 16, 392-395.

8. R. A. Messerly, T. A. Knotts, N. F. Giles and W. V. Wilding. Fluid Phase Equilib., $2017,449,104-116$.

9. S. Liu, C. Cao and Z. Li. J. Chem. Inf. Comput. Sci., 1998, 38, 387-394. 